OPEN

SUBJECT AREAS:

PHYSICAL

OCEANOGRAPHY

HYDROLOGY

Received

22 August 2014

Accepted

14 November 2014

Published

10 December 2014

Correspondence and requests for materials should be addressed to

(jingzhao198763@

(jingzhao198763@
tamu.edu)

\section{Intensified Diapycnal Mixing in the Midlatitude Western Boundary Currents}

\author{
Zhao Jing ${ }^{1,2} \&$ Lixin $W_{u^{2}}$
}

\begin{abstract}
'Department of Oceanography, Texas A\&M University, College Station, TX77840, USA, 2Physical Oceanography Laboratory/ Qingdao Innovation Center of Marine Science and Technology, Ocean University of China, Qingdao, China.
\end{abstract}

The wind work on oceanic near-inertial motions is suggested to play an important role in furnishing the diapycnal mixing in the deep ocean which affects the uptake of heat and carbon by the ocean as well as climate changes. However, it remains a puzzle where and through which route the near-inertial energy penetrates into the deep ocean. Using the measurements collected in the Kuroshio extension region during January 2005, we demonstrate that the diapycnal mixing in the thermocline and deep ocean is tightly related to the shear variance of wind-generated near-inertial internal waves with the diapycnal diffusivity $6 \times$ $10^{-5} \mathrm{~m}^{2} \mathrm{~s}^{-1}$ almost an order stronger than that observed in the circulation gyre. It is estimated that $45 \%-62 \%$ of the local near-inertial wind work $4.5 \times 10^{-3} \mathrm{Wm}^{-2}$ radiates into the thermocline and deep ocean and accounts for $42 \%-58 \%$ of the energy required to furnish mixing there. The elevated mixing is suggested to be maintained by the energetic near-inertial wind work and strong eddy activities causing enhanced downward near-inertial energy flux than earlier findings. The western boundary current turns out to be a key region for the penetration of near-inertial energy into the deep ocean and a hotspot for the diapycnal mixing in winter.

iapycnal mixing in the deep ocean affects the uptake of heat and carbon by the ocean as well as climate changes $^{1-4}$. To maintain the abyssal stratification, 2 TW energy is required to furnish the diapycnal mixing in the deep ocean (defined as the region below the main thermocline in this paper) ${ }^{1,5}$. Tidal dissipation in the open ocean is estimated to be only about $1 \mathrm{TW}^{6}$. It has been conjectured that the wind work on oceanic nearinertial motions, estimated between 0.5-1.4 $\mathrm{TW}^{7-9}$, may play an important role in closing the energy budget. However, observation $\mathrm{s}^{10}$ in the Northeastern Pacific indicated that only a minor (12\%-33\%) portion of nearinertial wind work was able to radiate into the deep ocean, similar to the earlier findings based on numerical simulations $s^{11,12}$. Therefore, it remains a puzzle where and through which route the near-inertial wind work penetrates into the deep ocean. Theoretical and numerical studies suggested that the downward radiation of near-inertial energy can be significantly enhanced in the presence of mesoscale eddies ${ }^{13-17}$. Given that the storm tracks associated with energetic near-inertial wind work are remarkably coincident with regions of strong eddy activities ${ }^{15}$, it might be possible that the midlatitude western boundary current region, especially the Kuroshio and its extension, is one of the key sites for the penetration of near-inertial energy flux. However, evaluating the relation between mixing and wind-generated near-inertial motions requires concurrent velocity and hydrographic measurements with high temporal resolution, which is still a formidable challenge in this region due to the unfavorable weather and oceanic environment in the storm seasons.

The strength of diapycnal mixing is typically measured by the turbulent kinetic dissipation rate estimated from microstructure measurements. Due to their high cost, the existing microstructure measurements in the Kuroshio and its extension are quite limited and are only confined to the upper $300 \mathrm{~m}^{18-20}$. In particular, none were implemented in the winter time due to the weather limitations, making it unable to sample the mixing associated with strong near-inertial wind forcing. Away from the Kuroshio front and below the mixed layer, internal waves make the dominant contribution to shear variance ${ }^{19-21}$, suggesting that the diapycnal mixing is mainly furnished by internal wave breaking. As an alternative, the diapycnal mixing can be inferred from the internal-wave induced finescale $\mathrm{O}(10-100 \mathrm{~m})$ strain and shear by using a finescale parameterization ${ }^{22-24}$. The long-term moorings deployed by the Kuroshio Extension System Study (KESS) provide an opportunity to assess the relation of wind-generated near-inertial internal waves and deep-ocean mixing. Each mooring was equipped with a McLane Moored Profiler moving vertically to sample the salinity, temperature, and horizontal velocity between $\sim 250-1500 \mathrm{~m}$. The time interval between successive profiles is typically about 15 hours. But it was reduced to 2 hours in January 4-22, 2005 for KESS Mooring 7 so that the diapycnal mixing and near-inertial signals can be estimated concurrently. There was also an up-looking Acoustic Doppler current profiler (ADCP) deployed at $\sim 250 \mathrm{~m}$. The horizontal velocity measured by ADCP is averaged hourly and is available throughout the deploy- 
ment. Here we will use the data of Mooring 7 to analyze the role of wind-generated near-inertial internal waves in modulating the diapycnal mixing in the deep ocean.

\section{Results}

Mooring 7 is located about $300 \mathrm{~km}$ to the south of the Kuroshio front where the sea surface temperature is marked by a sharp north-south gradient (Fig. 1a). In January 2005, a smooth thermocline is centered around $600 \mathrm{~m}$ with a maximum buoyancy frequency $N$ of $6.2 \times$ $10^{-3} \mathrm{~s}^{-1}$ (Fig. 1b). Within 300-1350 m, the shear associated with the large-scale background flow is 1-2 orders of magnitude smaller than $N$ (Fig. 1b), suggesting that the background flow is stable and the diapycnal mixing is probably furnished by internal wave breaking. The dissipation rate shows a similar pattern to $N$ (Fig. 1c). Both peak within the thermocline. The diapycnal diffusivity becomes larger with increasing depth in the upper $900 \mathrm{~m}$ after which depth it remains almost unchanged (Fig. 1d). In particular, the vertical mean diapycnal diffusivity between $300-1350 \mathrm{~m}$ is $6 \times 10^{-5} \mathrm{~m}^{2} \mathrm{~s}^{-1}$, much larger than $\sim 10^{-5} \mathrm{~m}^{2} \mathrm{~s}^{-1}$ observed in the circulation gyre $\mathrm{e}^{22,25,26}$.

Throughout 300-1350 m, the dissipation rate is tightly correlated to the near-inertial shear variance with correlation coefficients ranging from $0.4 \sim 0.6$ (Fig. 2). This suggests the important role of nearinertial internal waves in modulating the diapycnal mixing. The correlation coefficient does not show evident reduction with increasing depth, implying that the influence of near-inertial shear on diapycnal mixing may extend to deeper regions not sampled by the MMP. Unlike the near-inertial shear, the super-inertial shear and stratification have minor influences on the variation of dissipation rate. Their correlation coefficients range from $-0.2 \sim 0.3$ and are typically within $0.1 \sim 0.2$ (See Supplementary Table 1$)$. Therefore, it is the energetic near-inertial internal waves that play a major role in modulating the diapycnal mixing within $300-1350 \mathrm{~m}$.

To identify the origins of energetic near-inertial shear in January, we analyze its propagation direction. It is well known that vertical propagation of internal wave energy and shear variance is opposite to its phase propagation. Therefore, the upward- and downward-propagating internal waves can be separated in the frequency-vertical wavenumber space (the propagating direction is in the sense of energy and shear variance henceforth). The frequency-wavenumber spectrum of vertical shear exhibits pronounced peaks around the inertial frequency and wavenumber of $0.03 \mathrm{rad} \mathrm{m}^{-1}$ (Fig. 3a), suggesting the important contribution of near-inertial internal waves to the shear variance and thus diapycnal mixing. In particular, the peaks in the first and third quadrants are much stronger than those in the second and fourth quadrants, consistent with the dominant downward-propagating wavepackets.
As the frequency-wavenumber spectrum may be distorted by the horizontal advection, we further analyze the rotary spectrum of shear with respect to depth (Fig. $3 \mathrm{~b})^{27}$. The shear exhibits dominant clockwise rotation with increasing depth at wavenumbers smaller than $0.1 \mathrm{rad} \mathrm{m} \mathrm{m}^{-1}$ (wavelengths larger than $60 \mathrm{~m}$ ). For near-inertial internal waves, dominant clockwise rotation over counter-clockwise rotation is associated with downward energy propagation. Therefore, the rotary spectrum analysis is consistent with the frequency-wavenumber spectrum analysis. Both indicate that the energetic nearinertial shear in January is mainly furnished by the near-inertial wind work.

In January, the mean downward near-inertial energy flux $\bar{F}$ within $300-1350 \mathrm{~m}$ estimated from the frequency-wavenumber spectrum is $(2.4 \pm 0.4) \times 10^{-3} \mathrm{Wm}^{-2}$. Provided that the energy flux at the bottom $(1350 \mathrm{~m})$ is significantly smaller than that at the top $(300 \mathrm{~m}), \bar{F}$ is a reasonable estimate for the difference $\Delta F$ of energy flux at the top and the bottom (See the Method Section for details). Therefore, $\Delta F$ accounts for $42 \%-58 \%$ of the depth-integrated dissipation rate $4.8 \times 10^{-3} \mathrm{Wm}^{-2}$ at the same period, further supporting the important role of near-inertial energy in maintaining the diapycnal mixing.

The efficiency of downward radiation of near-inertial wind work can be evaluated by comparing the wind work and downward energy flux. The observed mean near-inertial wind work from December 2004 to January 2005 is $4.5 \times 10^{-3} \mathrm{Wm}^{-2}$. Here the wind work in December is included as the energy flux in early January within 300$1350 \mathrm{~m}$ may be furnished by the wind work in late December due to the propagation time. This suggests that about $45 \%-62 \%$ of the wind work in December and January is able to radiate into the deep ocean. The computed efficiency is more than twice the $12 \%-33 \%$ estimated in the Northeastern Pacific ${ }^{10}$. The enhanced downward radiation may be due to the vertical geostrophic vorticity $\zeta_{g}$ which shifts the lower bound of internal wave frequency from the Coriolis frequency $f$ to the effective Coriolis frequency $f_{\text {eff }}=f+\frac{1}{2} \zeta_{g}{ }^{13}$. In the Northern Hemisphere, this can accelerate the downward radiation of nearinertial energy in the negative- $\zeta_{g}$ region so that a larger portion of near-inertial energy can penetrate into the deep ocean before being dissipated $^{14-16}$. Mooring 7 is located in the region with negative $\zeta_{g}$ from January 4 to 14 (Fig. $4 \mathrm{a}$ ). The mean $\zeta_{g}$ during this period is $-0.06 f$. As most of the enstrophy is contained in the horizontal wavenumber band $(2-3) \times 10^{-5} \mathrm{rad} \mathrm{m}^{-1}$ (See Supplementary Fig S1), the gradient of $\zeta_{g}$ is much larger than the planetary vorticity gradient. Therefore, the geostrophic vorticity plays a dominant role in the propagation of near-inertial internal waves ${ }^{16}$. Within January $4-14$, there is pronounced downward radiation of near-inertial
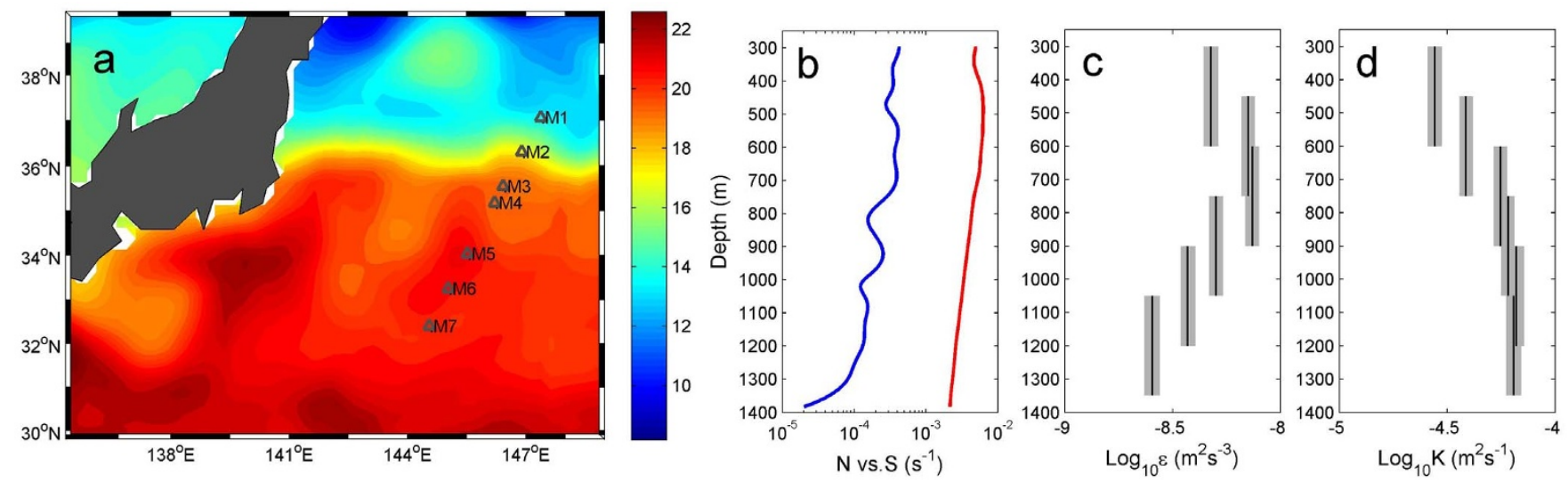

Figure 1 Energetic diapycnal mixing in January 2005 (a) Reynolds sea surface temperature on January 1, 2005 and location of KESS moorings.

(b) The mean buoyancy frequency (red) and shear magnitude (blue) associated with the large-scale background flow during January 4-22, 2005. (c) and

(d) Similar to (b) but for the dissipation rate and diffusivity with $90 \%$-confidence intervals derived from the bootstrap method. 

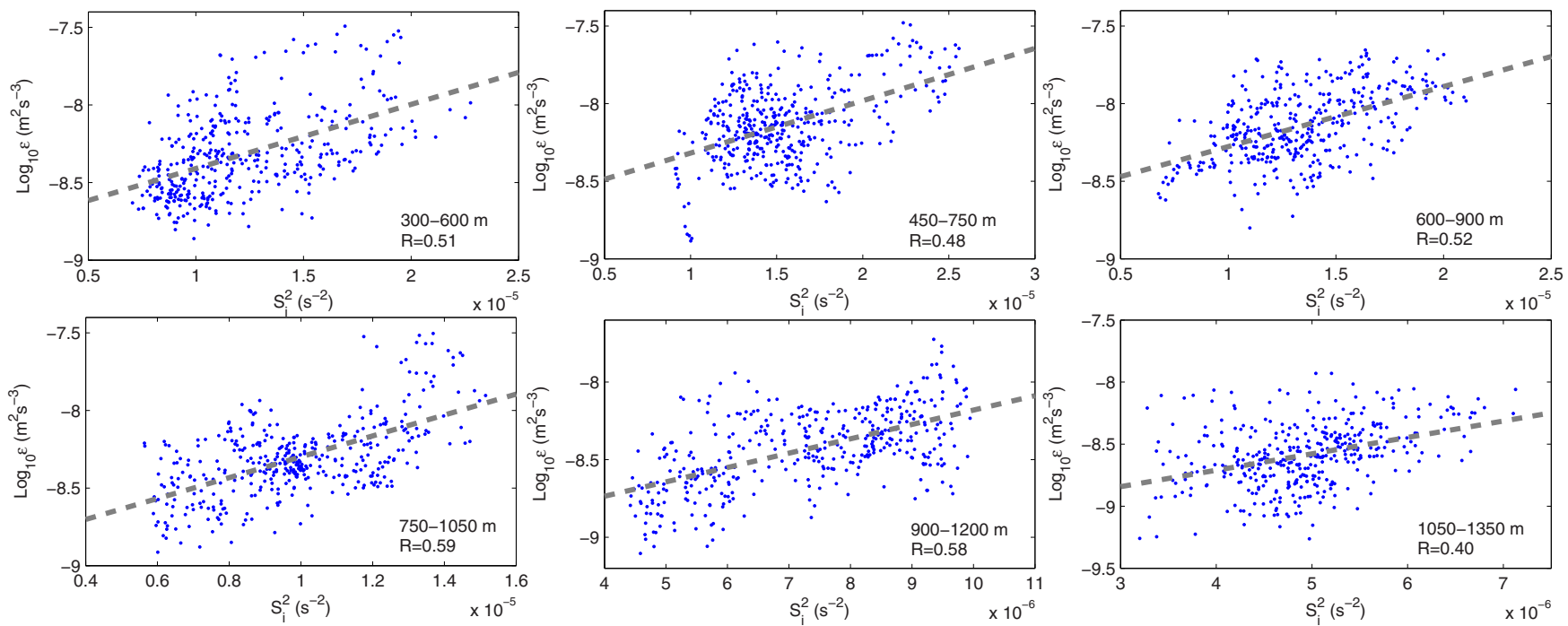

Figure $2 \mid$ Correlation of near-inertial shear variance $S_{i}^{2}$ to dissipation rate in January 2005 at different depth segments. $R$ denotes the correlation coefficient.

energy (Fig. 4b). The mean downward near-inertial energy flux is increased to $(3.5 \pm 0.6) \times 10^{-3} \mathrm{Wm}^{-2}$ during the period January $4-$ 14 but it is reduced to $(1.5 \pm 0.3) \times 10^{-3} \mathrm{Wm}^{-2}$ during the period January 14-22, suggesting the important role of negative geostrophic vorticity in draining near-inertial energy into the deep ocean. Furthermore, it is possible that not all the near-inertial energy is furnished by the wind work locally. In particular, the horizontal radiation of near-inertial energy may also play an important role in the energy budget. As demonstrated in the theoretical and numerical studies ${ }^{14,17}$, the near-inertial energy in the mixed layer tends to radiate from the positive $-\zeta_{g}$ region to the negative- $\zeta_{g}$ region horizontally. To test whether this idea also works in the reality, we analyze the correlation of near-inertial kinetic energy $Q_{i}^{\text {mix }}$ in the mixed layer to $\zeta_{g}$. Here $Q_{i}^{\text {mix }}$ is defined as the average within 0-50 m. But using a different mixed-layer depth, i.e., $100 \mathrm{~m}$, does not make any substantial impact on the conclusion. Before implementing the cor- relation analysis, the wind work, $\zeta_{g}$, and $Q_{i}^{\text {mix }}$ are binned for each 5day interval with each half of each bin overlapping to remove the irrelevant high-frequency variability. $Q_{i}^{\text {mix }}$ exhibits moderate correlation to $\zeta_{g}$ with a correlation coefficient $r_{\zeta}$ of -0.27 (significant at $<1 \%$ significance level based on a t-test), suggesting that $Q_{i}^{\text {mix }}$ is stronger when $\zeta_{g}$ is negative. This is consistent with the scenario where the near-inertial energy in the mixed layer tends to radiate from the positive- $\zeta_{g}$ region to the negative- $\zeta_{g}$ region. It should be noted that $r_{\zeta}^{2}$ is much smaller than $r_{W}^{2}$ where $r_{W}=0.59$ is the correlation coefficient between wind work and $Q_{i}^{\text {mix }}$. Therefore, the wind work plays a dominant role in furnishing the near-inertial motions in the mixed layer and may distort the relationship between $Q_{i}^{\text {mix }}$ and $\zeta_{g}$. To isolate the effect of geostrophic vorticity, we compare $Q_{i}^{\text {mix }}$ under negative- and positive- $\zeta_{g}$ conditions during the periods with weak wind forcing. As can be seen from Fig. $4 \mathrm{c}$ and $4 \mathrm{~d}, Q_{i}^{\text {mix }}$ is enhanced in
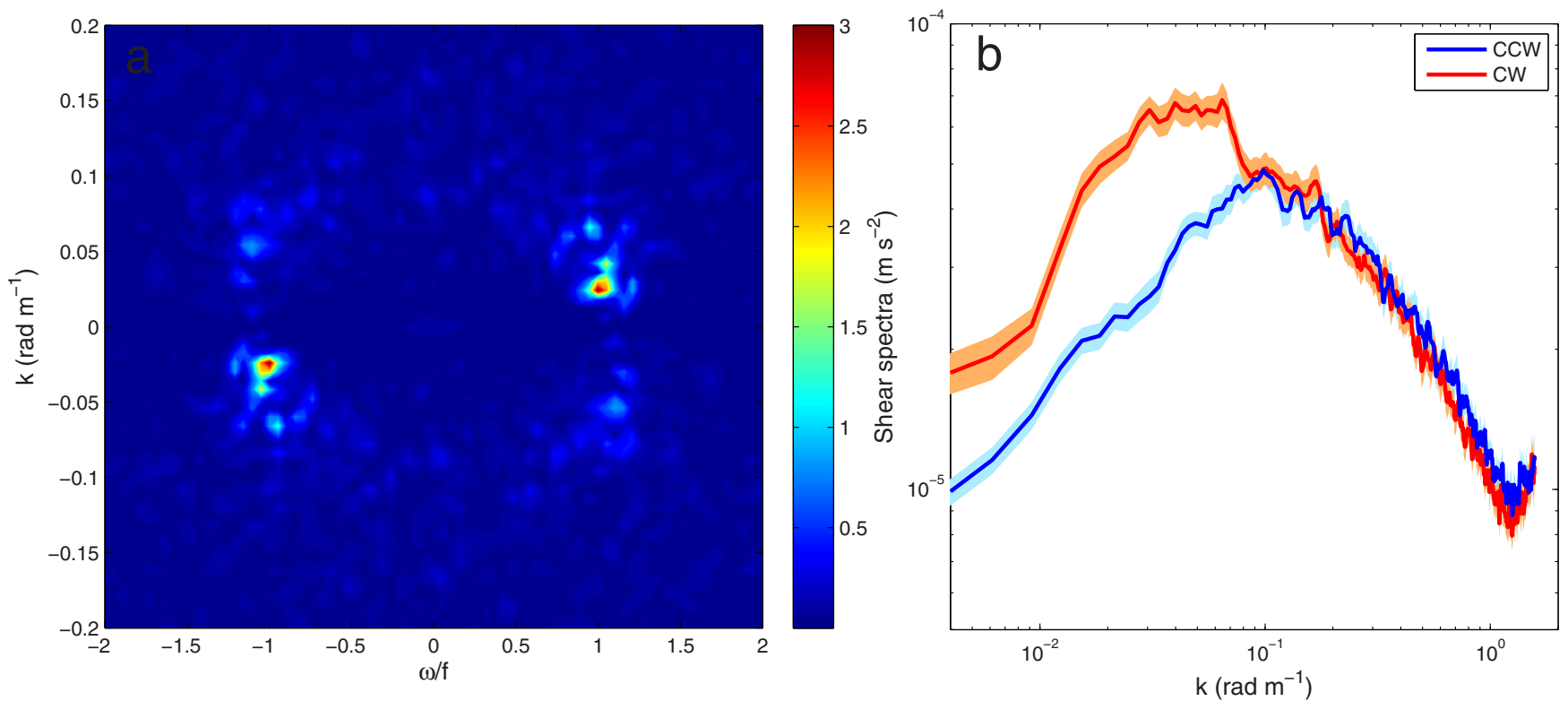

Figure 3 Downward radiation of near-inertial shear (a) The frequency-wavenumber spectrum (unit: $\mathrm{m} \mathrm{s}^{-1}$ ) of vertical shear. The spectrum in the first and third quadrants is associated with downward-propagating wavepackets while the spectrum in the second and fourth quadrants is associated with upward-propagating wavepackets. (b) The rotary spectrum of vertical shear. The red and blue lines represent the clockwise and counter-clockwise rotation with increasing depth, respectively. The shaded regions are the $90 \%$-confidence intervals computed from the bootstrap method. 

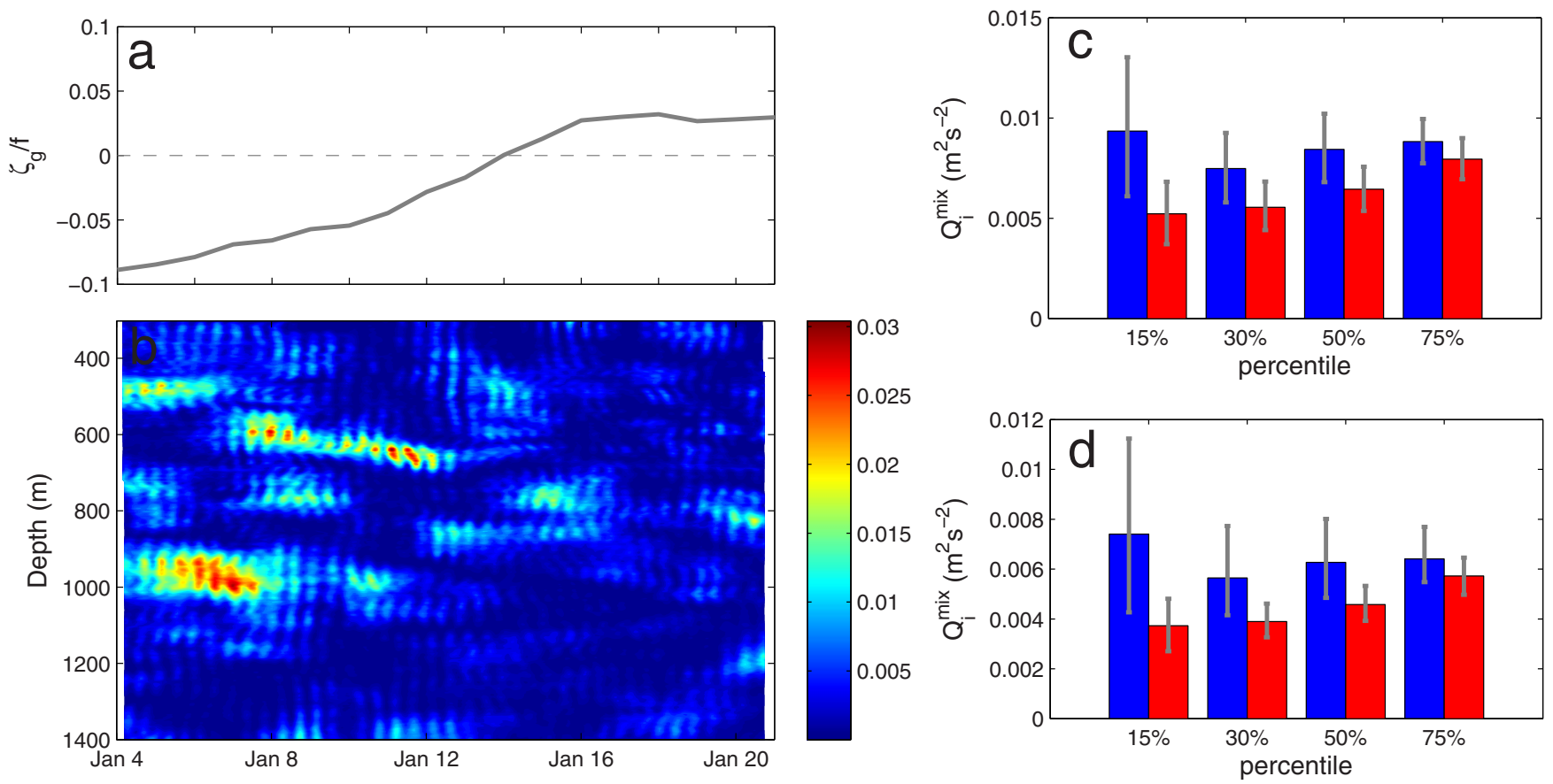

Figure 4 $\mid$ Influences of geostrophic vorticity on downward radiation of near-inertial energy (a) Time series of $\zeta_{g}$ normalized by $f$. (b) Near-inertial kinetic energy $Q_{i}^{2}$ in $\mathrm{m}^{2} \mathrm{~s}^{-2}$ obtained from the MMP measurements. (c) The composite analysis for mean $Q_{i}^{2}$ within $0-50 \mathrm{~m}$ under negative- (blue bar) and positive- $\zeta_{g}$ (red bar) conditions with weak wind forcing defined as wind work smaller than its $15 \%, 30 \%, 50 \%$, or $75 \%$ percentile. The errorbar is the $90 \%$ confidence interval computed from the bootstrap method. The values are derived from the ADCP records between June 2004 and January 2005.

(d) Similar to (c) but for mean $Q_{i}^{2}$ within $0-100 \mathrm{~m}$.

the negative- $\zeta_{g}$ condition. The enhancement becomes progressively more evident with the weakened wind forcing. For periods with wind work smaller than its $15 \%$ percentile, $Q_{i}^{\text {mix }}$ in the negative- $\zeta_{g}$ condition is twice that in the positive- $\zeta_{g}$ condition, suggesting the tendency of near-inertial energy to radiate from the positive- $\zeta_{g}$ region to negative- $\zeta_{g}$ region. The negative- $\zeta_{g}$ regions may act as chimneys through which the near-inertial wind work penetrates rapidly into the deep ocean.

The near-inertial wind work shows evident seasonality. It is significantly elevated in winter (See Supplementary Fig S2). The mean wind work from June to November 2004 is $1.5 \times 10^{-3} \mathrm{Wm}^{-2}$ while it increases to $4.5 \times 10^{-3} \mathrm{Wm}^{-2}$ in December 2004-January 2005 . Correspondingly, the near-inertial kinetic energy in the upper $200 \mathrm{~m}$ shows pronounced enhancement in December and January (See Supplementary Fig S2). If the wind-generated near-inertial internal waves played an important role in modulating the diapycnal mixing, a similar seasonal cycle would be expected in diapycnal mixing. This is confirmed by the observations. The diapycnal mixing in the upper 300-1350 m exhibits pronounced seasonal variation with much stronger dissipation rates in December and January (Fig. 5). The mean value in December and January is about 3 times of that in the other months. This provides further evidence for the significant contribution of near-inertial wind work to maintaining diapycnal mixing in the deep ocean.

In this study, we demonstrate the important role of wind-generated near-inertial internal waves in modulating the diapycnal mixing in the deep ocean at KESS Mooring 7. It should be noted that the elevated diapycnal mixing in winter and the enhanced downward near-inertial energy flux in the presence of negative geostrophic vorticity are common features in the Kuroshio and its extension (See Supplementary Fig S3 and S4), suggesting that the conclusions in this study are broadly representative there. Due to the strong eddy activities and energetic near-inertial wind work, the western boundary current turns out to be a key region for the penetration of near- inertial energy flux into the deep ocean and a hotspot for the diapycnal mixing in winter.

\section{Discussion}

In the past 50 years, the near-inertial wind work in the extra-tropical Pacific has increased by about $40 \%{ }^{7}$ probably due to the increased frequency and intensity of extra-tropical atmospheric cyclones ${ }^{28}$. As the near-inertial wind work plays an important role in furnishing the diapycnal mixing in the deep ocean, this may result in a strengthened Meridional Overturning Circulation and/or an elevated eddy kinetic energy at midlatitudes ${ }^{1,5}$. To capture these effects, high-resolution climate models are necessary to resolve the mesoscale eddies and near-inertial winds especially in the western boundary current regions.

\section{Methods}

Data. The in situ current and hydrographic data are obtained from the KESS moorings. Each mooring consisted of a subsurface float at $250 \mathrm{~m}$ with an uplooking Acoustic Doppler current profiler (ADCP), a McLane Moored Profiler (MMP), and current meters at greater depths. The horizontal velocity measured by ADCP is averaged hourly and is interpolated onto a $10-\mathrm{m}$ grid. The MMP samples horizontal velocity, temperature, and salinity from $250 \mathrm{~m}$ to $1500 \mathrm{~m}$ every $\sim 15 \mathrm{~h}$. But the time interval between successive profiles was reduced to $2 \mathrm{~h}$ for Mooring 7 between January 4-22, 2005. All the data have undergone quality control. A detailed description is available through the online access http://uskess. org/data_public.html.

The Kuroshio Extension Observatory (KEO) mooring was anchored at $32^{\circ} 21.0^{\prime} \mathrm{N}, 144^{\circ} 38.2^{\prime} \mathrm{E}$. It is always located within $10-15 \mathrm{~km}$ of KESS Mooring 7 . It measures the surface air pressure, relative humidity, air temperature, and winds with a temporal resolution of $10 \mathrm{~min}$. More details are at http://www.pmel.noaa. gov/keo/.

The mesoscale vorticity is computed from the merged satellite altimetry sea level anomaly (SLA) using the geostrophic relation. The daily SLA data are provided by AVISO on a horizontal grid of $1 / 3^{\circ}$.

Finescale parameterization. The turbulent dissipation rate can be expressed in terms of finescale strain and shear as ${ }^{22-24}$ 

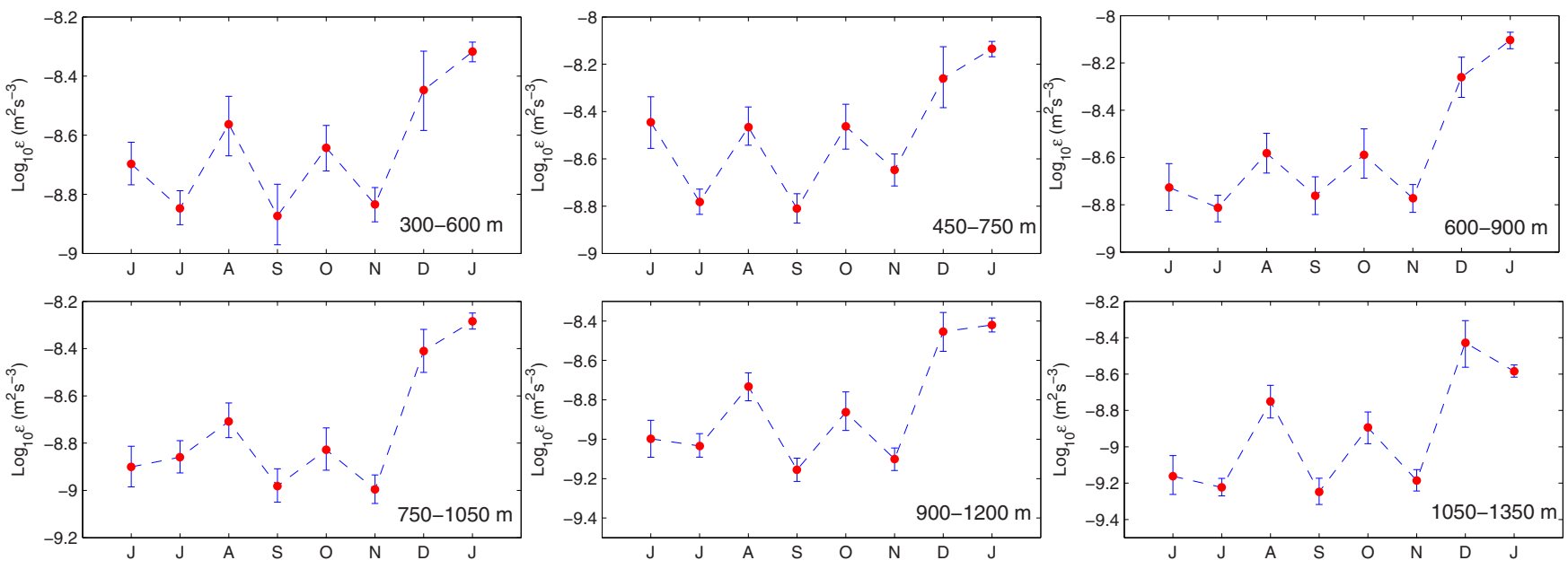

Figure $5 \mid$ Monthly mean dissipation rate in the different depth segments at Mooring 7 . The errorbar denotes the $90 \%$-confidence interval computed from the bootstrap method.

$$
\varepsilon=\varepsilon_{0} \frac{N^{2}}{N_{0}^{2}} \frac{<S_{z}^{2}>^{2}}{G M<S_{z}^{2}>^{2}} h_{1}\left(R_{\omega)}\right) j(f / N)
$$

where ${ }_{G M}<S_{z}^{2}>$ is shear variance from the Garrett-Munk model spectrum ${ }^{29}$ treated in the same way as the observed shear variance $\left\langle S_{z}^{2}\right\rangle$, and $R_{\omega}=\left\langle S_{z}^{2}\right\rangle /\left(N^{2}<\xi_{z}^{2}>\right)$ represents shear/strain variance ratio. The finescale parameterization is only applicable to the region away from the boundary layer and where internal wave breaking makes major contribution to the mixing. In addition, it requires that the wave-wave interactions dominate wave-mean flow interactions in the downscale energy cascade ${ }^{30}$. The relative importance of wave-mean flow interactions and wavewave interactions is measured as $r_{s}=8 S_{l} / N$ where $S_{l}$ is the magnitude of vertical shear associated with the large-scale background flow ${ }^{30}$. The finescale parameterization is valid when $r_{s}$ is smaller than $1^{30}$. With these conditions satisfied, previous observations ${ }^{23,24}$ indicate that estimates from finescale parameterization agree with microstructure measurements within a factor of 2 . The region $300-1350 \mathrm{~m}$ is well below the surface mixed layer. The background flow here is stable (Fig. 1b) and its shear is much smaller than that associated with internal waves, implying that the diapycnal mixing is furnished by internal wave breaking. Furthermore, the value of $r_{s}$ ranges from $0.1-0.7$, suggesting the dominance of wave-wave interactions over wavemean flow interactions. Therefore, the finescale parameterization is valid.

Internal wave shear and strain are estimated from horizontal velocity and buoyancy frequency ${ }^{22}$. Each vertical profile is divided into 300-m segments with each half of each segment overlapping. Then Fourier transform gives the spectral representation $\phi(k)$ for each segment using the multi-taper technique. Strain variance $\left\langle\xi_{z}^{2}\right\rangle$ and shear variance $\left\langle S_{z}^{2}>\right.$ is determined by integrating $\phi(k)$ from the lowest resolved wavenumber $k_{\min }=\frac{2 \pi}{150} \mathrm{rad} \mathrm{m}^{-1}$ out to a maximum wavenumber $k_{\max }$ so that

$$
<\xi_{z}^{2}>,<S_{z}^{2}>=\int_{k_{\min }}^{k_{\max }} \phi(k) d k=A
$$

Here $A$ is 0.13 for strain and 0.39 for shear, leading to a $k_{\max }=\frac{2 \pi}{16} \mathrm{rad} \mathrm{m}^{-1}$ for the GM spectrum ${ }^{29}$. This avoids underestimation of dissipation rates ${ }^{31}$ in case that the spectra become saturated at $k<\frac{2 \pi}{10} \mathrm{rad} \mathrm{m}^{-1}$. The GM strain and shear variance are computed over the same wavenumber band.

The diapycnal diffusivity can be expressed in the form of

$$
K=\Gamma \frac{\varepsilon}{N^{2}}
$$

where $\Gamma$ is mixing efficiency and typically taken to be $0.2^{32}$.

The shear and strain spectra in the upper $300-1350 \mathrm{~m}$ are consistent with the saturated finescale spectral theory (See Supplementary Fig S5) ${ }^{31}$, supporting the validity of the finescale parameterization ${ }^{30}$. The shear spectra seem to be contaminated by the measurement errors at $k>\frac{2 \pi}{16} \mathrm{rad} \mathrm{m}^{-1}$. But the contamination does not affect the computed dissipation rate for our choice of $A=0.39$ as the resulted $k_{\max }$ is typically smaller than $\frac{2 \pi}{16} \mathrm{rad} \mathrm{m}^{-1}$.

The frequency-wavenumber spectrum and downward near-inertial energy flux. The vertical shear is computed from the first-order difference of the horizontal velocity measured by MMP. The frequency-wavenumber spectrum $\Phi(\omega, k)$ of vertical shear is estimated using the 2-Dimensional Fourier transform. Then the vertical mean downward near-inertial energy flux within 300-1350 m can be computed as:

$$
\bar{F}=\int \frac{2 \omega^{2}}{\omega^{2}+f^{2}} \frac{\rho_{0} \Phi(\omega, k)}{2 k^{2}} c_{g z}(\omega, k) d \omega d k
$$

where $c_{g z}=-\frac{\omega^{2}-f^{2}}{2 \omega k}$ is the vertical group velocity and $\rho_{0}$ is the density of sea water. The integrand is integrated over the $(\omega, k)$ space where $c_{g z}<0$ and $f<|\omega|<1.4 f$. Before transform, the horizontal velocity is WKB-scaled and the vertical coordinate is WKB-stretched. Furthermore, the time coordinate is stretched in form of $d \tau=f_{\text {eff }} / f d t$ to account for the shift of the lower bound of internal wave frequency from $f$ to $f_{\text {eff }}=f+\frac{1}{2} \zeta_{g}$. Nevertheless, applying these modifications or not only has a minor influence on the computed downward near-inertial energy flux with a change less than $30 \%$.

The statistical confidence interval for downward near-inertial flux is difficult to estimate. Here the confidence interval is computed by evaluating the sensitivity of frequency-wavenumber spectrum on the window used before transform. Generally, smoothing $\Phi(\omega, k)$ tends to increase the downward energy flux. The rectangular window (no smoothing) yields the smallest value $2.0 \times 10^{-3} \mathrm{Wm}^{-2}$ while the Parzen and Chebyshev windows lead to the largest value $2.8 \times 10^{-3} \mathrm{Wm}^{-2}$.

Define $r_{F}$ as the ratio of $F_{b}$ to $F_{t}$ where $F_{t}$ and $F_{b}$ represent the flux at $300 \mathrm{~m}$ and $1350 \mathrm{~m}$, respectively. As $\bar{F}$ is approximately equal to $\frac{1}{2}\left(F_{t}+F_{b}\right)$, the difference of $F_{t}$ and $F_{b}$ can be expressed as

$$
\Delta F=\frac{2\left(1-r_{F}\right)}{1+r_{F}} \bar{F}
$$

For $r_{F}$ ranging from $0.1-0.5, \Delta F$ and $\bar{F}$ agree within a factor of 1.6. The exact value for $r_{F}$ is difficult to estimate but the following analysis suggests that it should be significantly smaller than 1 . Therefore, $\bar{F}$ is a reasonable estimate for $\Delta F$.

During January 4-22 2005, the mean $Q_{i}$ within $300-1350 \mathrm{~m}$ is about $3.3 \times$ $10^{-3} \mathrm{~m}^{2} \mathrm{~s}^{-2}$ while it decreases to $0.8 \times 10^{-3} \mathrm{~m}^{2} \mathrm{~s}^{-2}$ at $2000 \mathrm{~m}$ (computed from the Aanderaa current meter). The pronounced reduction of near-inertial energy with increasing depth cannot be simply explained by the varying stratification as the mean buoyancy frequency between $300-1350 \mathrm{~m}$ is only twice the value around $2000 \mathrm{~m}$ (The WKB theory predicts $Q_{i} \propto N$ ). Therefore, the near-inertial internal wave field below $1350 \mathrm{~m}$ is much weaker than that within $300-1350 \mathrm{~m}$, suggesting that $r_{F}$ should be significantly smaller than 1 . Otherwise, the bulk of near-inertial energy flux would radiate into the abyssal ocean, leaving a small portion to furnish near-inertial internal waves within $300-1350 \mathrm{~m}$. Such a scenario is inconsistent with much weaker near-inertial internal waves at $2000 \mathrm{~m}$ than those within $300-1350 \mathrm{~m}$.

Near-inertial wind work. The wind work on the near-inertial motion in the mixed layer can be computed directly as:

$$
W=\vec{\tau}_{i} \cdot \vec{u}_{i}
$$

where $\vec{u}_{i}$ and $\vec{\tau}_{i}$ are the near-inertial velocity in the mixed layer and wind stress, respectively. Here $\vec{u}_{i}$ is derived from the hourly ADCP measurements while the wind stress is acquired from the KEO Mooring. The near-inertial motion is isolated by band-pass filtering so that the frequencies between $0.8-1.4 f$ are retained.

1. Wunsch, C. \& Ferrari, R. Vertical mixing, energy and the general circulation of the oceans. Ann. Rev. Fluid Mech. 36, 281-412 (2004). 
2. Gregory, J. M. Vertical heat transports in the ocean and their effect on time dependent climate change. Clim. Dyn. 16, 501-515 (2000).

3. Saenko, O. \& Merrifield, W. On the effect of topographically enhanced mixing on the global ocean circulation. J. Phys. Oceanogr. 35, 826-834 (2005).

4. Richards, K. J., Xie, S.-P. \& Miyama, T. Vertical mixing in the ocean and its impact on the coupled ocean-atmosphere system in the Eastern Tropical Pacific. J. Climate 22, 3703-3719 (2009).

5. Munk, W. \& Wunsch, C. Abyssal recipes II: Energetics of tidal and wind mixing. Deep Sea Res. Part II 45, 1977-2010 (1998).

6. Jayne, S. R. \& St. Laurent, L. C. Parameterizing tidal dissipation over rough topography. Geophys. Res. Lett. 28, 811-814 (2001).

7. Alford, M. H. Improved global maps and 54-years history of wind-work on ocean inertial motions. Geophys. Res. Lett. 30, 1424 (2003).

8. Watanabe, M. \& Hibiya, T. Global estimates of the wind-induced energy flux to inertial motions in the surface mixed layer. Geophys. Res. Lett. 29, 1239 (2002)

9. Jiang, J., Lu, Y. \& Perrie, W. Estimating the energy flux from the wind to ocean inertial motions: The sensitivity to surface wind fields. Geophys. Res. Lett. 32, L15610 (2005).

10. Alford, M. H., Cronin, M. F. \& Klymak, J. M. Annual cycle and depth penetration of wind-generated near-inertial internal waves at ocean Station Papa in the Northeast Pacific. J. Phys. Oceanogr. 42, 889-909 (2012).

11. Zhai, X., Greatbatch, R. J., Eden, C. \& Hibiya, T. On the loss of wind-induced nearinertial energy to turbulent mixing in the upper ocean. J. Phys. Oceanogr. 39, 3040-3045 (2009)

12. Furuichi, N., Hibiya, T. \& Niwa, Y. Model-predicted distribution of wind-induced internal wave energy in the world's oceans. J. Geophys. Res. 113, C09034 (2008).

13. Kunze, E. Near-inertial propagation in geostrophic shear. J. Phys. Oceanogr. 15, 544-565 (1985).

14. Lee, D.-K. \& Niiler, P. P. The inertial chimney: The near-inertial energy drainage from the ocean surface to the deep layer. J. Geophys. Res. 103, 7579-7591 (1998).

15. Zhai, X., Greatbatch, R. J. \& Zhao, J. Enhanced vertical propagation of storminduced near-inertial energy in an eddying ocean channel model. Geophys. Res. Lett. 32, L18602 (2005).

16. Zhai, X., Greatbatch, R. J. \& Eden, C. Spreading of near-inertial energy in a $1 / 12^{\circ}$ model of the North Atlantic Ocean. Geophys. Res. Lett. 34, L10609 (2007).

17. Balmforth, N. J. \& Young, W. R. Enhanced dispersion of near-inertial waves in an idealized geostrophic flow. J. Mar. Res. 56, 1-40 (1998).

18. Nagai, T., Tandon, A., Yamazaki, H. \& Doubell, M. J. Evidence of enhanced turbulent dissipation in the frontogenetic Kuroshio Front thermocline. Geophys. Res. Lett. 36, L12609 (2009).

19. Nagai, T., Tandon, A., Yamazaki, H., Doubell, M. J. \& Gallager, S. Direct observations of microscale turbulence and thermohaline structure in the Kuroshio Front. J. Geophys. Res. 117, C08013 (2012).

20. Kaneko, H., Yasuda, I., Komatsu, K. \& Itoh, S. Observations of the structure of turbulent mixing across the Kuroshio. Geophys. Res. Lett. 39, L15602 (2012).

21. Rainville, L. \& Pinkel, R. Observations of energetic high-wavenumber internal waves in the Kuroshio. J. Phys. Oceanogr. 34, 1495-1505 (2004).

22. Kunze, E., Firing, E., Hummon, J. M., Chereskin, T. K. \& Thurnherr, A. M. Global abyssal mixing inferred from lowered ADCP shear and CTD strain profiles. J. Phys. Oceanogr. 36, 1553-1576 (2006).

23. Polzin, K. T., Toole, J. M. \& Schmitt, R. D. Finescale parameterizations of turbulent dissipation. J. Phys. Oceanogr. 25, 306-328 (1995).
24. Gregg, M. C., Sanford, T. B. \& Winkel, D. P. Reduced mixing from the breaking of internal waves in equatorial ocean waters. Nature 422, 513-515 (2003).

25. Gregg, M. C. Diapycnal mixing in the thermocline: A review. J. Geophys. Res. 92, 5249-5286 (1987).

26. Polzin, K., Toole, J., Ledwell, J. \& Schmitt, R. Spatial variability of turbulent mixing in the abyssal ocean. Science 276, 93-96 (1997).

27. Leaman, K. D. \& Sanford, T. B. Vertical energy propagation of inertial waves: A vector spectral analysis of velocity profiles. J. Geophys. Res. 80, 1975-1978 (1975).

28. Graham, N. E. \& Diaz, H. F. Evidence for Intensification of North Pacific Winter Cyclones since 1948. Bull. Amer. Meteor. Soc. 82, 1869-1893 (2001).

29. Gregg, M. C. \& Kunze, E. Internal wave shear and strain in Santa Monica Basin. J. Geophys. Res. 96, 16709-16719 (1991).

30. Polzin, K. L., Garabato, A. C. N., Huussen, T. N., Sloyan, B. M. \& Waterman, S. Finescale parameterizations of turbulent dissipation. J. Geophys. Res. 119, 1383-1419 (2014).

31. Gargett, A. E. Do we really know how to scale the turbulent kinetic energy dissipation rates due to break of oceanic internal waves? J. Geophys. Res. 95, 15971-15974 (1990).

32. Osborn, T. R. Estimates of the local rate of vertical diffusion from dissipation measurements. J. Phys. Oceanogr. 10, 83-89 (1980).

\section{Acknowledgments}

This work is supported by China National Natural Science Foundation (NSFC) Key Project (41130859), National Major Research Plan of Global Change (2013CB956201), and NSFC-Shandong Joint Fund for Marine Science Research Centers. Z.J. is partly supported by the China Scholarship Council. We thank Kuroshio Extension System Study, Kuroshio Extension Observatory, and AVISO for providing the data through online accesses.

\section{Author contributions}

Z.J. performed the data analysis and contributed to writing of this paper. L.W. contributed to the central idea and editing of this paper.

\section{Additional information}

Supplementary information accompanies this paper at http://www.nature.com/ scientificreports

Competing financial interests: The authors declare no competing financial interests.

How to cite this article: Jing, Z. \& Wu, L. Intensified Diapycnal Mixing in the Midlatitude Western Boundary Currents. Sci. Rep. 4, 7412; DOI:10.1038/srep07412 (2014).

This work is licensed under a Creative Commons Attribution-NonCommercialShareAlike 4.0 International License. The images or other third party material in this article are included in the article's Creative Commons license, unless indicated otherwise in the credit line; if the material is not included under the Creative Commons license, users will need to obtain permission from the license holder in order to reproduce the material. To view a copy of this license, visit http:// creativecommons.org/licenses/by-nc-sa/4.0/ 